\title{
Neurotoxicity of halogenated hydroxyquinolines: clinical analysis of cases reported outside Japan
}

\author{
G. B A U M G A R T N R , M.J. G A W E L, H. E. K A E S E R, \\ C. A. PA L L IS, F. CLIF F OR D R OSE, H. H. S C H A U M B R G, \\ P. K. THOM A S, A N D N. H. W A D I A
}

From the Neurologische Universitäts-Klinik, Zürich and Neurologische Universitäts-Klinik, Basel, Switzerland, Charing Cross Hospital, Royal Postgraduate Medical School, Royal Free Hospital, London, England, Albert Einstein College of Medicine, New York, USA, and J. J. Group of Hospitals, Bombay, India

SUMMARY An analysis is presented of 220 cases of possible neurotoxic reactions to halogenated hydroxyquinolines reported from outside Japan. In 80 cases insufficient information was available for adequate comment and in 29 a relationship to the administration of clioquinol could be excluded. Of the remainder, a relationship to clioquinol was considered probable in 42 and possible in 69 cases. In six of the probable cases the neurological disturbance consisted of an acute reversible encephalopathy usually related to the ingestion of a high dose of clioquinol over a short period. The most common manifestation, observed in 15 further cases, was isolated optic atrophy. This was most frequently found in children, many of whom had received clioquinol as treatment for acrodermatitis enteropathica. In the remaining cases, a combination of myelopathy, visual disturbance, and peripheral neuropathy was the most common manifestation. Isolated myelopathy or peripheral neuropathy, or these manifestations occurring together, were infrequent. The onset of all manifestations (except toxic encephalopathy) was usually subacute, with subsequent partial recovery. Older subjects tended to display more side effects. The full syndrome of subacute myelo-optic neuropathy was more frequent in women, but they tended to have taken greater quantities of the drug.

About 30 years ago, cases began to appear in Japan of a syndrome of subacute onset in which myelopathy, optic neuropathy, and peripheral neuropathy occurred in various combinations, preceded by abdominal symptoms. Persistent symmetrical dysaesthesiae, usually affecting the legs and lower trunk, were a common feature. Motor involvement was less common and took the form of a spastic or spastic/ataxic paraparesis or, more rarely, of hypotonic weakness in the lower limbs. Bilateral visual impairment occurred in a proportion of cases, sometimes resulting in permanent blindness. There was a tendency to remission, but many cases remained severely disabled. As many as 10000 individuals are reported to have been affected, and the disorder became a substantial social problem. The condition came to be termed

Address for reprint requests: Professor P. K. Thomas, Royal Free Hospital, Pond Street, London NW3 2QG.

Accepted 16 May 1979 subacute myelo-optico neuropathy or SMON (Tsubaki et al., 1965). Much emphasis was originally placed on early gastrointestinal symptoms which were considered to be of neurogenic origin (Ando and Sobue, 1969). Although they were initially held to be a cardinal feature of the disorder (Kono, 1971) less importance was subsequently attached to this aspect. A number of other symptoms including hallucinations and disturbances of consciousness were also noted. Hanakago and Sugiyama (1971) and Ogawa et al. (1975) described patients with acute confusional states.

A green fur was observed on the tongue in some of the patients (Takasu et al., 1970). The pigment was found to be an iron chelate of clioquinol (Imanari and Tamura, 1970). After the demonstration by Igata et al. (1970) of the same substance in the urine and faeces, SMON came to be attributed to clioquinol (Yoshioka and Tamura, 1970; Tsubaki et al., 1971), although several 
Japanese authorities had earlier favoured various viral aetiologies. Further studies from Japan, summarised by Kono $(1971,1978)$ and Yamamoto (1978), suggested that the daily dose and duration of administration of clioquinol were of significance, and that elderly women were more often affected than age-matched men, but considerable variations in susceptibility were observed. Once clioquinol was withdrawn in Japan in 1970, the incidence of new cases fell dramatically although some new cases still occurred (Shimada and Kosaka, 1973). Doubts regarding the interpretation of the epidemiological data, including the significance of those cases in which there was no history of clioquinol ingestion, have been discussed by Meade (1975), Lee (1978a, b), Shigematsu (1978), Shigematsu and Yanagawa (1978), and Yamamoto (1978).

Despite the fact that hydroxyquinolines have been in widespread use throughout the world since their introduction in 1934, reports of neurological side effects have remained infrequent. They have been more numerous since the Japanese experience, and have included not only cases resembling the SMON syndrome, but also instance; of isolated optic atrophy in children, often in cases of acrodermatitis enteropathica, and examples of acute encephalopathy. In view of the continuing use of clioquinol-containing preparations for gastrointestinal disorders in many parts of the world and in order to assess the pattern of neurological disturbance that mav arise from ingestion of these preparations. we thought it important to analyse the reported instances of neurological disorders attributed to clioquinol outside Japan.

A literature survev revealed descriptions of 95 cases in which neurological effects from clioquinol were claimed or considered possible. A further 125 cases reported to the main manufacturers of clioquinol (Ciba-Geigy Ltd) have been included. Enquiries from two other manufacturing companies did not yield any unpublished cases. An analysis has, therefore, been made of these 220 cases which constitute all those known to us from 1935 to mid 1977.

\section{Methods}

A panel of neurologists met on repeated occasions and after detailed consideration of the available information, reached a consensus as to the nature of the clinical features exhibited by the reported cases and their possible relationship to clioquinol administration. Some of the difficulties entailed have been stressed by Pallis (1978) and Rose (1978). Six of the eight members of the panel had had the opportunity of examining cases of clioquinol neurotoxicity in Japan through the courtesy of the physicians concerned.

As the syndrome of subacute myelo-optic neuropathy is defined in terms of involvement of particular anatomical pathways in the nervous system, the case reports were analysed and an attempt made to attribute symptoms and signs to lesions of the spinal cord, visual pathways, or peripheral nervous system. This was termed the semeiological rating and was undertaken independently of any assessment of the attributability to clioquinol of the syndromes reported. Cases of isolated optic atrophy occurring in childhood and of toxic encephalopathy were also identified. The likelihood of each case being caused by clioquinol was then assessed. This was termed the attributability rating.

\section{SEMEIOLOGICAL RATING}

The neurological symptoms and signs were assessed as follows.

Peripheral neuropathy Involvement of the peripheral nervous system was recorded if one or more of the following features were present: (a) bilateral distal sensory loss in the limbs; (b) tendor wे areflexia (usually confined to the lower limbs); (c)을 weakness or significant wasting considered to bes due to lower motor neurone involvement, whethe or not supported by electromyographic evidencen of denervation; (d) electrophysiological evidence of peripheral neuropathy derived from nerve conduc tion studies. Although these represent generally accepted clinical criteria for the presence of peripheral neuropathy, the qualification must be added that without electrophysiological or pathological confirmation of degeneration of motor or sensory axons or of segmental demyelination in the peripheral nerves, a clear statement that peripheral neuropathy exists cannot be made. Thus sensory loss or tendon areflexia could both be the result of selective intramedullary degeneration of the centrally directed branches of the primary sensory neurones. This question will be considered in greater detail in the Discussion.

Myelopathy Involvement of the spinal cord was accepted in the presence of one or more of the following: (a) spasticity; (b) weakness in the legs of "pyramidal" distribution; (c) extensor plantar responses (brisk tendon reflexes in isolation were not accepted as implying myelopathy); (d) a sensory level on the trunk.

Paraesthesiae/dysaesthesiae These were occasionally assigned to a separate category in view of difficulty in deciding whether they were attributable to disturbances of the spinal cord or of per- 
ipheral nerve function. To warrant acceptance, such symptoms had to be bilateral and involve both lower limbs. Evanescent paraesthesiae or sensory symptoms confined to the face, to a single limb, or to both limbs on one side were excluded.

Optic neuropathy Involvement of the visual pathways was accepted in the presence of bilateral visual deficit not attributable to other causes such as refractive error, cataract, cycloplegia, glaucoma, or retinal degeneration. The presence of optic atrophy or of a demonstrable scotoma was not considered essential.

Abdominal symptoms Attention was also given to gastrointestinal disturbances, whether preceding or accompanying the neurological symptoms. These were not analysed as the available information was insufficient to decide whether such symptoms were of primary alimentary origin or related to disturbances of the innervation of the gastrointestinal tract.

\section{ATTRIBUTABILITY RATING}

This was undertaken independently of the semeiological rating. Its purpose was to determine the likelihood of the neurological symptoms and signs being caused by intoxication with clioquinol. The assessment was attempted whether or not the clinical features were those of a syndrome that could be designated subacute myelo-optic neuropathy. The implication of this approach was that some neurological manifestations (such as acute encephalopathy) could convincingly be attributed to clioquinol, whereas others that embraced features of the SMON syndrome (such as isolated myelopathy or peripheral neuropathy) might not. The principal considerations of this rating were: (a) onset-that is, the time of onset of the neurological symptoms in relation to clioquinol ingestion; (b) evolution - that is, the variation in the neurological state in relation to clioquinol administration. This involved the detection of those cases which improved on cessation or deteriorated on continued administration of clioquinol, or even improved despite continued medication; (c) differential diagnosis-that is, the assessment of the likelihood of the neurological disorder being due to causes other than clioquinol. The cases were then allocated to one of the following four categories.

Probable clioquinol neurotoxicity In these there was a suggestive temporal relationship between the neurological disorder and clioquinol ingestion. No alternative aetiology for the neurological disorder could be established. Regression or complete remission of the symptoms after discontinuation of the drug was considered as confirmation that the neurological disturbance was drug-induced. Possible clioquinol neurotoxicity Cases were allocated to this category when the neurological features appeared during clioquinol administration (or within six weeks of its cessation) but the criteria of the preceding category could not be fulfilled. No definite alternative diagnosis was obvious. An interval of six weeks was allowed in view of the interval that may elapse between the onset of neuropathy and a single exposure to certain neurotoxic agents such as triorthocresyl phosphate or diphtheria toxin.

Neurotoxicity unlikely Cases were allocated to this category if the neurological symptoms only became apparent between six weeks and six months after the cessation of clioquinol administration, if the neurological symptoms regressed although the administration of clioquinol was continued, of if there were more probable aetiologies for the neurological disorder. An interval of up to six months was chosen as in Japan cases were accepted if they had received clioquinol within this period before the onset of symptoms (Shigematsu, 1975).

No relationship to clioquinol Cases were allotted to this category when the initial or subsequent neurological symptoms first manifested themselves before treatment with clioquinol, or six months or more after the last dose of the drug.

\section{Results}

The information available from the published cases was of better quality than that available from those reported directly to the manufacturers. In 27 of the 95 published cases it was considered that insufficient information was available for adequate assessment, and that in four of them any relationship to clioquinol administration was unlikely or could be dismissed. Such exclusions included the following reports.

An early case report by Barros (1935) mentioned one patient with unspecified side effects and gave no information on dosage. In 20 patients reported by Gholz (1962) and Gholz and Arons (1964) there were no individual case descriptions such as would allow the kind of assessment we are attempting. The male child aged 20 months reported by Aguiler Diaz (1971) had developed a transient disturbance of gait with no apparent physical signs. McEwen (1971) described a man of unreported age who developed retrobulbar neuritis while in an allergy trial. Insufficient information was given and other explanations were possible. The 45 year old man reported by Spillane (1971) developed transient diplopia, ataxia, dysarthria, 
and right sided paraesthesiae. Cerebral ischaemia seems a more plausible diagnosis. Insufficient information was provided concerning the 26 year old woman (Skobba, 1971) who developed impaired vision after taking up to $2.5 \mathrm{~g}$ of clioquinol daily for many years. Kean (1972) described a 33 year old man who, on a trip to Mexico, developed pains in his arms and shoulders after giardiasis that had been treated with clioguinol. The information was insufficient for diagnostic purposes. Panizon (1972) reported a 2 year old girl considered to be a typical case of SMON. Insufficient clinical information was provided, and no details concerning the dosage of clioquinol were given. Grenier et al. $(1972,1973)$ described a 10 year old boy who developed an acute symmetrical polyneuropathy in whom the Guillain-Barré syndrome seemed a more likely diagnosis. The 42 year old woman recorded by Thurn (1973) with a history of polypharmacomania probably had multiple sclerosis. A relationship to clioquinol also appeared implausible in the 46 year old woman (Tay, 1973) who developed a myelopathy, optic neuropathy, and paraesthesiae two weeks after taking a two day course of clioquinol. The symptoms improved after four to six weeks, but relapses occurred six and eight months later, without further clioquinol medication. A 9 year old girl who developed an unsteady gait and bilateral paraesthesiae up to groin level was recorded by Wadia (1977). Her gait improved within 24 hours of stopping clioquinol. She was taking metronidazole at the same time which was also discontinued. The author himself expressed doubt as to the diagnosis and stated that the clinical picture resembled a transient transverse myelitis.

In 53 of the 125 unpublished cases reported to the manufacturers, it was considered that insufficient information had been provided concerning clinical features, dosage, or time relationship to clioquinol administration for an adequate assessment, and that in 25 a causal relationship to clioquinol administration could be excluded. In a further four there were no specific neurological symptoms, or paraesthesiae only were reported, which precluded further analysis. The remaining 43 were included in the overall review.

CASES OF PROBABLE CLIOQUINOL NEUROTOXICITY There were 42 cases in which a relationship to clioquinol administration seemed probable, of which 29 were from published material and 13 from cases reported to the manufacturer. Information on these particular cases was derived from the following publications: Etheridge and Stewart (1966); Berggren and Hansson (1966, 1968);
Kaeser and Scollo-Lavizzari (1970); Kaeser and Wüthrich (1970); Danis (1971); Kjaersgaard (1971); Osterman (1971); Van Balen (1971); Billson et al. (1972); Bron et al. (1972); Cambier et al. (1972); Pedersen and Christiansen (1972); Van Beeck and Scholten (1972); Castaigne et al. (1973); De Crousaz et al. (1973); Heilig and Thaler (1973, 1974); Reich and Jünemann (1973); Wadia (1975, 1977); Ferrier and Eadie (1973); GarciaPerez et al. (1974); Papuzinski and WilmowskaPietruszynska (1974); Vitale et al. (1974); De Sèze et al. (1975); Lefebvre et al. (1975); Otte et al. (1976, 1977); Carr et al. (1977).

\section{Pattern of neurological involvement}

Neurological involvement included acute confusional states complaints of paraesthesiae, and objective signs of optic atrophy, myelopathy, or peripheral neuropathy. Patients exhibited these features either singly or in various combinations. It became apparent during the analysis that the manifestations could be separated into three groups.

The first comprised patients who developed and $\vec{\circ}$ acute confusional state after the ingestion of clioquinol over a short period of time, usually im high dosage. These were termed toxic encephalo 8 pathy. The second consisted of patients, most often children, with optic atrophy as the soles neurological feature. Thirdly, there were cases with optic atrophy, myelopathy, and peripheraf. neuropathy, or instances where these manifestas tions occurred singly (except for optic atrophy) or where only two of the three features were present. The numbers in these different groups, both from published and unpublished reports, are given in Table 1.

Isolated optic atrophy myelo-optic neuropathy, and toxic encephalopathy constituted the largest categories. Of the 16 children with optic atrophy, there were 11 in whom a relationship of the symptoms to the ingestion of clioquinol was considered probable. Of these six had been prescribed clioquinol for treatment of acrodermatitis enteropathica.

Table 1 Pattern of neurological involvement in cases of probable clioquinol neurotoxicity

\begin{tabular}{lccc}
\hline & Published & Unpublished & Total \\
\hline Toxic encephalopathy & 4 & 2 & 6 \\
Isolated optic atrophy & 8 & 7 & 15 \\
Myelo-optic neuropathy & 10 & 1 & 11 \\
Optic atrophy/myelopathy & 3 & 1 & 4 \\
Myelopathy/neuropathy & 1 & 2 & 3 \\
Isolated myelopathy & 1 & 0 & 1 \\
Isolated neuropathy & 1 & 0 & 1 \\
Neuropathy/optic atrophy & 1 & 0 & 1 \\
Total & 29 & 13 & 42 \\
\hline
\end{tabular}
(a) 
Relationship to age (Table 2)

There was a tendency for patients with more side effects to be in the older age groups. For instance while all 11 patients with three side effects were over the age of 40 years, only six of the 23 with a single side effect were in this age group. The interpretation of this relationship is not simple since among those who had only one or two types of side effect was the group of children with isolated optic atrophy. However, even when this group was subtracted, there remained a tendency for a relationship between age and the number of side effects.

\section{Relationship to sex (Tables 3 and 4)}

In the cases where there was considered to be a probable relationship of symptomatology to clioquinol ingestion, the female : male ratio was $26: 16$. This was similar to the previously reported sex prevalence of toxic reactions attributed to clioquinol in Japan. While females were more

Table 2 Relationship of number of side effects to age in patients with probable clioquinol neurotoxicity

\begin{tabular}{lrrrr}
\hline Age group $(y r)$ & \multicolumn{2}{l}{ Number of side effects } & \multicolumn{1}{c}{$\begin{array}{l}\text { Total } \\
\text { number }\end{array}$} \\
\cline { 2 - 4 } & 1 & 2 & 3 & \\
\hline $0-10$ & 10 & 1 & 0 & 11 \\
$11-20$ & 2 & 0 & 0 & 2 \\
$21-30$ & 3 & 0 & 0 & 3 \\
$31-40$ & 2 & 0 & 0 & 2 \\
$41-50$ & 4 & 0 & 2 & 6 \\
$51-60$ & 2 & 4 & 3 & 9 \\
$61-70$ & 0 & 1 & 1 & 2 \\
$71-80$ & 0 & 2 & 5 & 7 \\
Total & 23 & 8 & 11 & 42 \\
\hline
\end{tabular}

Table 3 Relationship of type of side effect to sex in cases of probable clioquinol neurotoxicity

\begin{tabular}{lcc}
\hline Side effect & Male & Female \\
\hline Toxic encephalopathy (TE) & 3 & 3 \\
Isolated optic atrophy (O) & 7 & 8 \\
Myelo-optic neuropathy (MON) & 3 & 8 \\
Optic atrophy/myelopathy (MO) & 2 & 2 \\
Myelopathy/neuropathy (MN) & 0 & 3 \\
Isolated myelopathy (M) & 1 & 0 \\
Isolated neuropathy (N) & 0 & 1 \\
Neuropathy/optic atrophy (NO) & 0 & 1 \\
Total & 16 & 26 \\
\hline
\end{tabular}

Table 4 Relationship of number of side effects to sex in cases of probable clioquinol neurotoxicity

\begin{tabular}{lrrr}
\hline $\begin{array}{l}\text { Number of side } \\
\text { effects }\end{array}$ & Male & Female & Total \\
\hline 1 & 11 & 12 & 23 \\
2 & 2 & 6 & 8 \\
3 & 3 & 8 & 11 \\
Total & 16 & 26 & 42 \\
\hline
\end{tabular}

likely to develop the full syndrome of myelooptic neuropathy $(8: 3)$, optic atrophy in childhood was found equally in both sexes $(8: 7)$.

\section{Dosage and duration of clioquinol intake}

Mean intakes associated with different constellations of symptoms varied considerably, but the ranges were so wide (from $18 \mathrm{~g}$ to $15 \mathrm{~kg}$ ), and the patterns of intake so diverse, as to make any evaluation meaningless. Thus reported cases with the full syndrome of myelo-optic neuropathy, for instance, had taken a total dose of $21,53,65,270$, $700,750,1100,6000,6570$, and $1500 \mathrm{~g}$ respectively. All the patients who presented with a toxic encephalopathy had only ingested a total small dose ( $7.5 \mathrm{~g}$ or less) but this had been taken over a short period (24 hours or less).

In none of the cases in which symptoms were probably attributable to clioquinol was there a significant interval between cessation of drug ingestion and the onset of the neurological disturbance. In most cases symptoms started while the patients were still taking the drug.

As already noted, there was a preponderance of women among the more seriously affected cases. But it was also evident that women had ingested substantially more clioquinol than men. If this is taken into account, the preponderance of serious involvement in females becomes less obvious. It is likely that women were no more susceptible to the neurotoxic effects of clioquinol than men, but merely that they ingested more of the drug. They were also, presumably, lighter in weight.

\section{Mode of onset (Table 5)}

With the exception of toxic encephalopathy, most neurological complications came on subacutely. This was true not only for patients with the full syndrome of myelopathy, visual disturbance, and peripheral neuropathy, but also for those with incomplete forms. In two patients with the complete syndrome, the onset had been very insidious. In five there was insufficient information to allow comment.

Table 5 Mode of onset of neurological disorder in cases of probable clioquinol neurotoxicity*

\begin{tabular}{|c|c|c|c|c|c|c|c|c|c|}
\hline $\begin{array}{l}\text { Mode of } \\
\text { onset }\end{array}$ & $T E^{\dagger}$ & $O$ & $M O N$ & $M O$ & $M N$ & $M$ & $N$ & NO & Total \\
\hline $\begin{array}{l}\text { Acute } \\
\text { Subacute } \\
\text { Chronic }\end{array}$ & 6 & 10 & $\begin{array}{l}9 \\
2\end{array}$ & 4 & 3 & 1 & 1 & 1 & $\begin{array}{r}6 \\
29 \\
2\end{array}$ \\
\hline
\end{tabular}




\section{Outcome (Table 6)}

In most patients, irrespective of the mode of presentation, partial recovery had occurred. One patient exhibiting the full syndrome died of renal failure unrelated to clioquinol ingestion. In five cases information about the subsequent course of the illness was either insufficient or totally lacking.

CASES OF POSSIBLE CLIOQUINOL NEUROTOXICITY

In 69 cases (35 published, 34 unpublished), it was considered that a relationship between the neurological disorder and clioquinol ingestion could not be excluded. The publications from which the cases in this group were derived are as follows: Barros (1935); Busse-Grawitz (1935); Strandvick and Zetterström (1968) Kaeser and Wüthrich (1970); McEwen and Constantinopoulos (1970); McEwen (1971); Skobba (1971); Terry (1971); Bron et al. (1972); Cambier et al. (1972); Cohen and Streifler (1972); Drukker and Lindenburg (1972); Grenier et al. (1972, 1973); Pannekoek (1972); Selby (1972); Tournilhac and Flori 1972); Boergen (1973); Laterre et al. (1973); Reich (1973); Wadia (1975, 1977); Bajc (1974); Dahl (1974); Gendre et al. (1974); Mamoli et al. (1975); Tournilhac (1975); Froissart et al. (1976).

The types of neurological disturbance found in these cases are outlined in Table 7 . In view of the more tenuous relationship to drug administration,

Table 6 Clinical outcome in cases of probable clioquinol neurotoxicity*

\begin{tabular}{|c|c|c|c|c|c|c|c|c|c|}
\hline Outcome & $T E \dagger$ & $O$ & MON & $M O$ & $M N$ & $M$ & $N$ & NO & Total \\
\hline Full recovery & 4 & 2 & 1 & 1 & 1 & 1 & & & 10 \\
\hline $\begin{array}{l}\text { Partial } \\
\text { recovery }\end{array}$ & 2 & 4 & 4 & & & & 1 & & 16 \\
\hline No recovery & & 6 & 4 & & & & & & 10 \\
\hline Death & & & $1 \ddagger$ & & & & & & 1 \\
\hline
\end{tabular}

*In five cases, the clinical outcome could not be assessed. The total number is, therefore, less than in Tables $1-4$.

+ Abbreviations as in Table 3.

$\ddagger$ Unrelated to clioquinol.

Table 7 Pattern of neurological involvement in cases of possible clioquinol neurotoxicity

\begin{tabular}{lccc}
\hline & Published & Unpublished & Total \\
\hline Toxic encephalopathy & 1 & 2 & 3 \\
Isolated optic atrophy & 5 & 5 & 10 \\
Myelo-optic neuropathy & 4 & 2 & 6 \\
Optic atrophy/myelopathy & 1 & 2 & 3 \\
Myelopathy/neuropathy & 5 & 6 & 11 \\
Isolated myelopathy & 6 & 6 & 12 \\
Isolated neuropathy & 9 & 7 & 16 \\
Neuropathy/optic atrophy & 2 & 2 & 4 \\
Uncertain & 2 & 2 & 4 \\
Total & 35 & 34 & 69 \\
\hline
\end{tabular}

these cases were not analysed further. It is of interest that the clinical pattern differed from that found in cases considered more probably related to clioquinol. Examples of isolated neuropathy and myelopathy were the most numerous. In four cases (two published, two unpublished) it was not possible to ascribe the symptoms to a particular neurological lesion.

\section{Discussion}

NEUROTOXICITY OF HALOGENATED

HYDROXYQUINOLINES

Toxic encephalopathy An acute confusional state caused by clioquinol emerged as a relatively welldefined entity. Such cases had been recognised in Japan (Hanakago and Sugiyama, 1971; Ogawa et al., 1975), but have been more fully documented in non-Japanese reports (Kaeser and ScolloLavizzari, 1970; Kaeser and Wüthrich, 1971; Kjaersgaard, 1971; Ferrier and Eadie, 1973). The clinical picture consisted of drowsiness, mental confusion, disorientation, hallucinations, and headache with subsequent amnesia for events duringo the episode. This often followed ingestion of large amount of the drug over a short period. The patients reported by Kjaersgaard (1971) had taker $4 \mathrm{~g}$ over a 14 hour period, and the pharmaciso described by Kaeser and Scollo-Lavizzari (1970 had consumed no less than $7.5 \mathrm{~g}$ in under 24 hours The disturbance usually subsided completely withir a few days.

Isolated optic atrophy The majority of cases were in children, in many of whom clioquinol was being given for acrodermatitis enteropathica. This genetic disorder was formerly uniformly fatal, but was found to respond to treatment with halogenated hydroxyquinolines in high dosage (Dillaha et al., 1953). Optic atrophy in children who had received prolonged treatment with these preparations was first recognised in 1966 (Berggren and Hansson, 1966), and the possibility of drug toxicity was raised. This view was strengthened after the Japanese experience with clioquinol (Fleischer et al., 1974; Romaine and Lachman, 1974). The literature now contains a number of reports of optic atrophy in children with acrodermatitis enteropathica who had received long-term high dosage treatment with halogenated hydroxyquinolines (Etheridge and Stewart, 1966; Berggren and Hansson, 1966; Pannekoek, 1972; Reich, 1973; Reich and Jünemann, 1973; Garcia-Perez et al., 1974; Carr et al. 1977). The reason for the selective vulnerability of the optic nerves at this age is unknown.

Acrodermatitis enteropathica has recently been found to be the result of zinc deficiency (Moyna- 
han and Barnes, 1973). Since there is some evidence that zinc deficiency may lead to optic atrophy, the question has been raised at to whether optic atrophy in patients with acrodermatitis enteropathica may be related to zinc deficiency and not to the toxic effects of the drug (Leopold, 1978). The lack of previous reports of optic atrophy in earlier accounts of untreated acrodermatitis enteropathica could be related to the longer survival of patients on hydroxyquinoline treatment. This cannot, however, be the whole explanation, as cases of isolated optic atrophy have been reported in children without acrodermatitis enteropathica who have been treated with halogenated hydroxyquinolines (Van Balen, 1971; Billson et al., 1972; Reich and Billson, 1973).

Myelo-optic neuropathy Examples of isolated myelopathy or neuropathy, or of a syndrome suggesting a combination of myelopathy and neuropathy, were infrequent. There was a single instance of optic atrophy combined with a myelopathy that was probably attributable to clioquinol.

The fully developed clinical syndrome of subacute myelo-optic neuropathy (SMON) as described in Japan (Tsubaki et al., 1965) consists of a sensory deficit over the legs and lower trunk associated with painful dysaesthesiae, a spastic paraparesis with exaggerated knee jerks and extensor plantar responses (but often absent ankle jerks), and bilateral visual disturbances which may amount to optic atrophy. A similar clinical picture was observed in some cases reviewed in the present study. In general, these conformed to the Japanese descriptions.

\section{PATHOLOGY OF CLIOQUINOL NEUROTOXICITY}

No pathological studies have been reported in cases of acute encephalopathy in man, as none has been fatal. Püschner and Fankhauser (1969), Krinke et al. (1978) and others found necrotic lesions of ischaemic type in the hippocampus and amygdaloid nuclei in animals given lethal or sublethal doses of halogenated hydroxyquinolines that had caused acute encephalopathy with convulsions.

Pathological studies in Japan have demonstrated degenerative changes affecting the visual pathways, the lateral corticospinal tracts of the lower spinal cord, and the rostral portions of the gracile fasciculi (Tsubaki et al., 1965). This pattern of neuropathological change has been confirmed experimentally in animals, both by Japanese (Tateishi et al., 1973) and non-Japanese (Schaumburg et al., 1978) workers. The pattern of abnormality was a symmetrical distal axonal degeneration that advanced in a proximal direction towards the cells of origin in a "dying-back" fashion. Peripheral neuro- pathy has always been considered an important component of SMON, and yet an analysis of the published reports by Thomas (unpublished) has yielded the conclusion that involvement of the peripheral nervous system both in man and in the cxperimental studies in animals may have been overemphasised. Schaumburg et al. (1978), in an ultrastructural study, have recently found that there is no involvement of the peripheral nervous system in dogs administered clioquinol despite the presence of widespread distal axonal degeneration in the central nervous system. Furthermore, Tateishi (1977) and Worden et al. (1978) failed to detect any changes in the peripheral nervous system in animals similarly intoxicated, even at a stage when optic nerve and posterior column lesions were apparent in paraffin sections. It is, therefore, possible that clioquinol gives rise to a selective distal axonopathy confined or largely restricted to the central nervous system. This constitutes a highly unusual pattern of neuropathological change, with interesting theoretical implications.

The question arises as to the explanation of signs normally interpreted as indicative of peripheral nerve involvement, in particular loss of the ankle jerks, in cases of presumed clioquinol intoxication. The loss of the ankle jerks could be cxplained if the degeneration, in addition to involving the distal portions of the dorsal root fibres in the gracile fasciculi, also affected the branches distributed to the anterior horn cells involved in the monosynaptic tendon reflex. The ankle jerk could then be lost without any peripheral neuropathy as such, that is without any degeneration of the axons of the primary sensory neurones in the peripheral nerves. Distal sensory loss in the legs could also be explained by a selective degeneration of the centrally directed branches of the secondary sensory neurones. This latter proposal is supported by the finding of changes in the distal axons of the spinocervical tract of dogs intoxicated with clionuinol (Krinke et al., unpublished).

Unequivocal evidence of peripheral neuropathy can be obtained by the demonstration of appropriate abnormalities of sensory conduction or of axonal loss in sensory nerve biopsies. Alternatively, evidence of loss of motor axons by detection of denervation, either electromyographically or on muscle biopsy, can be sought. Such information was rarely available for the cases that have been reviewed in this study. It is noteworthy that in the nine probable or possible cases of SMON reported from Bombay by Wadia (1977) only one was considered to have peripheral nerve involvement. This was a 60 year old woman who complained of weak- 
ness and dysaesthesiae in her legs who showed bilaterally exaggerated knee jerks, absent ankle jerks, and extensor plantar responses. Motor and sensory conduction in the lower limbs was "slightly slowed." Most of his cases were examples of myelopathy with or without associated optic neuropathy.

The evidence for peripheral nerve involvement in cases of presumed clioquinol neurotoxicity is, therefore, not entirely satisfactory. If peripheral neuropathy does occur, it is possible that species differences exist and that the pattern of neural damage in man differs from that seen in the dog (Schaumburg et al., 1978). Further observations of the effects of clioquinol in primates, with combined morphological and electrophysiological studies, are therefore warranted.

\section{GEOGRAPHY OF CLIOQUINOL NEUROTOXICITY}

This study has shown that neurological side effects from clioquinol have been found throughout the world. Yet the high concentration of cases in Japan remains an enigma. The possibilities of interacting environmental factors or genetic susceptibility have been raised, but remain unsubstantiated. The present analysis of cases reported from outside Japan has indicated that in a high proportion (about half), a relationship to clioquinol was unlikely or difficult to establish. How far this is true of the Japanese cases is unknown. Such epidemiological questions fall outside the scope of the present study.

We wish to thank Ciba-Geigy Ltd for making available all of their unpublished case reports.

\section{Note}

Since completing this paper, a study by Katahira et al. (1978) has come to our attention. This includes a brief survey of reports of possible cases of neurotoxic reactions to halogenated hydroxyquinolines published outside Japan between 1970 and 1977.

\section{References}

Aguiler Diaz, M. L. F. (1971). Un nouveau symptome dans l'acrodermatite enteropathique: la demarche ataxique. Bulletin de la Société Française de Dermatologie et de Syphiligraphie, 78, 259-260.

Ando, K., and Sobue, I. (1969). Abdominal and neurological symptoms of myeloneuropathy with abdominal disorders. Saishin Igaku, 24, 2440-2450 (in Japanese).

Bajc, O. (1974). Myeloneuropathie nach Oxychinolinen: neurologische, elekromyographische und mikroskopische Befunde bei einen Fall. Schweizer
Archiv für Neurologie, Neurochirurgie und Psychiatrie (Zurich), 155, 308.

Barros, E. (1935). Amebas, y mas amebas. Semana Médica (Buenos Aires), 42, 907-908.

Berggren, L., and Hansson, O. (1966). Treating acrodermatitis enteropathica. Lancet, 1, 52.

Berggren, L., and Hansson, O. (1968). Absorption of intestinal antiseptics derived from 8-hydroxyquinolines. Clinical Pharmacology and Therapeutics, 9, 67-70.

Billson, F. H., Reich, J., and Hopkins, I. J. (1972). Visual failure in a patient with ulcerative colitis treated by clioquinol. Lancet, 1, 1015-1016.

Boergen, K. P. (1973). Optikusschäden durch oxychinolinhaltige Antidiarrhoica? Klinische Monatsblätter für Augenheilkunde, 163, 217-219.

Bron, H. L. N. M., Korten, J. J., Pinckers, A. J. L. G., and Majoor, C. L. H. (1972). Subacute myelooptico-neuropathie na het gebruik van grote hoeveelheden joodchloorhydroxychinolone (Enterovioform). Nederlands Tijdschrift voor Geeneskunde, 166, 1615-1617.

Busse-Grawitz, P. (1935). Nuevas orientaciones en la terapeutica de la amebiasis. Semana Médica, 42, 525-529.

Cambier, J., Masson, M., Berkman, N., and Dairou R. (1972). Neuropathie sensitive et névrite optique. Nouvelle Presse Médicale, 1, 1991-1992.

Carr, W. G. L., Bowen, R. A., and Horner, F. A. (1977). Iodochlorhydroxyquin and optic nerve damage. Canadian Medical A ssociation Journal, 116 251.

Castaigne, P., Rondot, P., Lenoel, Y., Dumas, J.-L. R. and Autret, A. (1973). Myélopathie sévère, neuro pathie périphérique et névrite optique survenues akō cours d'un traitement par la chloroiodoquine (clio? quinol). Thérapie, 28, 393-400.

Cohen, D., and Streifler, M. (1972). Hydroxyquinoline derivatives and the nervous system. Harefuah, 83, 7.

Dahl, K. B. (1974). Acrodermatitis enteropathica behandlet med jodkloroksykinolin. Ugeskift for Laeger, 136, 263-265.

Danis, P. (1971). Névrite optique et clioquinol. Bulletin de la Société Belge d'Ophtalmologie, 159, 671675.

De Crousaz, G., Voumard, Ch., and De Werra, P. (1973). A nephropathy in the genesis of SMON? Lancet, 1, 378.

De Sèze, S., Feldmann, J. L., Vitale, C., Hurault, A., Weisbecker, J., and Bechetoille, M. (1975). Neuromyélite optique subaiguë après chloroidoquinone. Semaine des Hopitaux de Paris, 51, 203.

Dillaha, C. J., Lorincz, A. L., and Aavik, O. R. (1953). Acrodermatitis enteropathica. Review of the literature and report of a case successfully treated with Diodoquin. Journal of the American Medical Association, 152, 509-512.

Drukker, J., and Lindenburg, P. A. W. (1972). Beiderzijdse opticusatrofie bij een kind van anderhalf jaar die wellicht een gevlog is van toediening van joodchloorhydroxychinoline (Enterovioform). Neder- 
lands Tijdschrift voor Geneeskunde, 116, 16181620.

Etheridge, J. E., and Stewart, G. T. (1966). Treating acrodermatitis enteropathica. Lancet, 1, 261-262.

Ferrier, T. M., and Eadie, M. J. (1973). Clioquinol encephalopathy. Medical Journal of Australia, 2, 1008-1009.

Fleischer, D. I., Hepler, R. S., and Landau, J. W. (1974). Blindness during diiodohydroxyquin (Diodoquin) therapy: a case report. Pediatrics, 54, 106-108.

Froissart, M., Morcamp, D., and Mizon, J.-P. (1976). Myélo-neuropathie sensitivomotrice après absorption de chloroiodoquinone. Nouvelle Presse Médicale, 5, 863.

Garcia-Perez, A., Castro, C., Franco, A., and Escribano, R. (1974). A case of optic atrophy possibly induced by quinoline in acrodermatitis enteropathica. British Journal of Dermatology, 90, 453455.

Gendre, J.-P., Barbanel, Cl., Degos, J.-D., and Le Quintrec, Y. (1974). Neuropathie sensitivomotrice grave: un cas après absorption de clioquinol, chez un insuffisant rénal. Nouvelle Presse Médicale, 3, 2395-2398.

Gholz, L. M. (1962). Long term prophylactic control of amebiasis and shigellosis. American Journal of Tropical Medicine and Hygiene, 11, 452-454.

Gholz, L. M., and Arons, W. L. (1964). Prophylaxis and therapy in amebiasis and shigellosis with iodochlorhydroxyquin. American Journal of Tropical Medicine and Hygiene, 13, 396-401.

Grenier, B., Rolland, J.-C., Casenave, C., and Desbuquois, G. (1972). Myéloradiculonévrite subaiguë et traitement par la chloro-iodoxyquinoléine. Archives Francaises de Pédiatrie, 29, 1015.

Grenier, B., Rolland, J.-C., Kiffer, A., and Maupas, Ph. (1973). Myéloradiculonévrites subaiguës et chloroiodoxyquinoléine: intoxication ou pathologie virale. Nouvelle Presse Médicale, 2, 1076.

Hanakago, R., and Sugiyama, N. (1971). Mental symptoms in myeloneuropathy with abdominal symptoms. Rinsho-Shinkeigaku (Clinical Neurology), 11, 51-53 (in Japanese).

Heilig, P., and Thaler, A. (1973). Subakute Myelooptico-neuropathie (SMON). Klinische Monatsblätter für Augenheilkunde, 163, 643-644.

Heilig, P., and Thaler, A. (1974). Subakute Myelooptikoneuropathie (SMON). Klinische Monatsblätter für Augenheilkunde, 164, 386-388.

Igata, A., Hasebe, M., and Tsuji, T. (1970). On the green pigment found in SMON patients: two cases excreting greenish urine. Nippon Iji Shinpo (Japanese Journal of Medicine), 2421, 25-28 (in Japanese).

Imanari, T., and Tamura, Z. (1970). Detection of chinoform from green fur on the tongue of SMON patients. Igaku no Ayumi (Progress in Medicine), 75, 547-548 (in Japanese).

Kaeser, H. E., and Scollo-Lavizzari, G. (1970). Acute cerebral disturbances after high doses of hydroxyquinoline derivative. German Medical Monthly, 15, 465-468.
Kaeser, H. E., and Wüthrich, R. (1970). Zur Frage der Neurotoxizität der Oxychinolone. Deutsche Medizinische Wochenschrift, 95, 1685-1688.

Katahira, K., Teshima, K., Kuzuhara, S., and Kono, R. (1978). An international survey on the recent reports concerning intoxication with halogenated oxyquinoline derivatives and the regulations against their use. Annual Report for 1977, pp. 195-207. SMON Research Commission: Japan.

Kean, B. H. (1972). Subacute myelo-optic neuropathy. A probable case in the United States. Journal of the American Medical Association, 220, 243-244.

Kjaersgaard, K. (1971). Amnesia after clioquinol. Lancet, 1, 1086.

Kono, R. (1971). Subacute myelo-optico-neuropathy, a new neurological disease prevailing in Japan. Japanese Journal of Medical Science and Biology, 24, 195-216 (in Japanese).

Kono, R. (1978). A review of the SMON studies in Japan. In Epidemiological Issues in Reported DrugInduced Illnesses: SMON and other Examples, pp. 121-136. Edited by M. Gent and I. Shigematsu' McMaster University Library Press: Hamilton, Ontario.

Krinke, G., Pericin, C., Thomann, P., and Hess, R. (1978). Toxic encephalopathy with hippocampal lesions. Zentralblatt für Vetinärmedizin A, 25, 277 296.

Laterre, E.-C., Stevens, A., Goffin, L., and Velghe, L. (1973). Myélopathie subaiguë (SMON) après absorption d'hydroxyquinoleines. Nouvelle Presse Médicale, 2, 2550.

Lee, J. A. H. (1978a). Data on clioquinol and SMON. Lancet, 1, 738.

Lee, J. A. H. (1978b). Data on clioquinol and SMON. Lancet, 1, 1108.

Lefebvre, P., Heraut, L., Gaudineau, R., Ille, H., and Ribot, Ch. (1975). Myélopathie et névrite optique retrobulbaire après ingestion prolongée de chloroiodoquinone. Medicine et Armées, 3, 260.

Leopold, I. H. (1978). Zinc deficiency and visual impairment? American Journal of Ophthalmology, 85, 871-875.

McEwen, L. M. (1971). Neuropathy after clioquinol. British Medical Journal, 4, 169-170.

McEwen, L. M., and Constantinopoulos, P. (1970). The use of a dietary and antibacterial regime in the management of intrinsic allergy. Annals of Allergy, 28, 256-266.

Mamoli, B., Thaler, A., Heilig, P., and Siakos, G. (1975). Subakute Myelo-optico-neuropathie (SMON) nach Clioquinolmedikation. Journal of Neurology (Berlin), 209, 139-147.

Meade, T. W. (1975). Subacute myelo-optic neuropathy and clioquinol. An epidemiological case history for diagnosis. British Journal of Preventive and Social Medicine, 29, 157-169.

Moynahan, E. J., and Barnes, P. M. (1973). Zinc deficiency and a synthetic diet for lactose intolerance. Lancet, 1, 676-677.

Ogawa, S., Sugai, Y., and Niwa, K. (1975). Group 
multiple occurrence of chinoform poisoning disease. Igaku No Ayumi, 94, 206-209 (in Japanese).

Osterman, P. O. (1971). Myelopathy after clioquinol treatment. Lancet, 1, 544.

Otte, G., De Coster, W., Thiery, E., De Renck, J., and Van Der Ecken, H. (1976). Subacute myelooptic neuropathy: a toxic or viral etiology? Acta Neurologica Belgica, 76, 331-334.

Otte, G., De Coster, W., Thiery, E., De Renck, J., and Van Der Ecken, H. (1977). Ultrastructural study of a muscle biopsy from a patient with SMON. Journal of Neurology (Berlin), 215, 91102.

Pallis, C. (1978). Observations on the differential diagnosis of SMON. In Epidemiological Issues in Reported Drug-Induced Illnesses: SMON and other Examples, pp. 152-166. Edited by M. Gent and I. Shigematsu. McMaster University Library Press: Hamilton, Ontario.

Panizon F. (1972). Cited by Selby, G. (1972). Lancet, 1, 123-125.

Pannekoek, J. H. (1972). Neurotoxische verschijnselen na clioquinol (Enterovioform). Nederlands Tijd schrift voor Geneeskunde, 116, 1611-1615.

Papuzinski, M., and Wilmowska-Pietruszynska, A. (1974). Neurological complications during treatment of acrodermatitis enteropathica with oxyquinoline derivatives. Pediatria Polska, 49, 13931397.

Pedersen, K. K., and Christiansen, N. (1972). Akut og kronisk kliokinolintoxikation. Ugeskrift for Laeger, 134, 1526-1528.

Püschner, H., and Fankhauser, R. (1969). Neuropathologische Befunde bei experimentelle Vioform: Vergiftung der weisen Maus. Schweizer Archiv für Tierheilkunde, 111, 371-379.

Reich, H. (1973). Acrodermatitis enteropathica: Gefahr arzneimittelbedingter Erblindung. Klinische Wochenscrift, 51, 1024.

Reich, H., and Jünemann, G. (1973). Acrodermatitis enteropathica: Retinopathie durch lebensrettende Chinolinpräparate. Klinische Monatsblätter für Augenheilkunde, 162, 112.

Reich, J. A., and Billson, F. H. (1973). Toxic optic neuritis: clioquinol ingestion in a child. Medical Journal of Australia, 2, 593-595.

Romaine, R. A., and Lachman, A. B. (1974). Acrodermatitis enteropathica-like clinical findings in two children. Archives of Dermatology, 109, 96-97.

Rose, F. C. (1978). On the diagnosis of subacute myelo-optic neuropathy (SMON) outside Japan. In Epidemiological Issues in Reported Drug-Induced Illnesses: SMON and other Examples, pp. 271-282. Edited by M. Gent and I. Shigematsu. McMaster University Library: Hamilton Ontario.

Schaumburg, H. H., Spencer, P. S., Krinke, G., Thomann, P., and Hess, R. (1978). The CNS distal axonopathy in dogs intoxicated with clioquinol. Journal of Neuropathology and Experimental Neurology, 37, 686a.

Selby, G. (1972). Subacute myelo-optic neuropathy in
Shigematsu, I. (1975). Subacute myelo-opticoneuropathy (SMON) and clioquinol. Japanese Journal of Medical Science and Biology, 28, 35-55. (In Japanese.)

Shigematsu, I. (1978). A review of epidemiological studies on SMON. In Epidemiological Issues in Reported Drug-Induced Illnesses: SMON and other Examples, pp. 167-171. Edited by M. Gent and I. Shigematsu. McMaster University Library Press: Hamilton, Ontario.

Shigematsu, I., and Yanagawa, H. (1978). Data on clioquinol and SMON. Lancet, 1, 945.

Shimada, Y., and Kosaka, K. (1973). New cases of SMON in Japan. Lancet, 1, 268.

Skobba, T. J. (1971). Optikusaffeksioner ved bruk av hydrosykinoliner. Tidskrift for den Norske Laegeforenung, 1829.

Spillane, J. D. (1971). SMON. Lancet, 1, 1371-1372.

Strandvick, B., and Zetterström, R. (1968). Amaurosis after broxyquinoline. Lancet, 1, 922-923.

Takasu, T., Igata, A., and Toyokura, Y. (1970). On the green tongue observed in SMON patients. Igaku no Ayumi (Progress in Medicine), 72, 539 (in Japanese).

Tateishi, J. (1977). Morphometric evaluation of the spinal root ganglia of beagle dogs intoxicated with chinoform. In Reports of the SMON Research Commission. Japan Lingua Services: Tokyo.

Tateishi, J., Kuroda, S., Saito, A., and Otsuki, S. (1973). Experimental myelo-optic neuropathy in- $\mathbb{Q}$ duced by clioquinol. Acta Neuropathologicag (Berlin), 24, 304-320.

Tay, C. H. (1973). SMON in Singapore. Lancet, 1, 1519.

Terry, S. I. (1971). Transient dysaesthesiae and pertô sistent leucocytosis after clioquinol therapy.? British Medical Journa!, 3, 745.

Thurn, G. (1973). Beitrag zur Neurotoxizität der Oxychinoline. Klinische Monatsblätter für Augenheilkunde, 163, 760-762.

Tournilhac, V. (1975). La myélo-optico neuropathie subaiguë japonaise: á propos de deux observations. Thesis, Clermond-Ferrand.

Tcurnilhac, M., and Flori, B. (1972). Syndrome radiculocordonal postérieur et chloroiodoquinone. Nouvelle Presse Médicale, 1, 3132.

Tsubaki, T., Honma, Y., and Hoshi, M. (1971) Neurological syndrome associated with clioquinol. Lancet, 1, 696-697.

Tsubaki, T., Toyokura, Y., and Tsukagoshi, H. (1965). Subacute myelo-optico-neuropathy following abdominal symptoms: a clinical and pathological study. Japanese Journal of Medicine, 4, 181-184 (in Japanese).

Van Balen, A. Th. (1971). Toxic damage to the optic nerve caused by iodochlorhydroxyquinoline (Enterovioform). Ophthalmolog:ca, 163, 8-9.

Van Beeck, J. A., and Scholten, J. B. (1972). Polyneuropathie na langdurig gebruik van clioquinol (Enterovioform). Nederlands Tijdschrift voor Geneeskunde, 116, 1621-1622. 
Vitale, C., Feldmann, J. L., Hubault, A., Weisbecker, J., Bechetoille, A., and De Sèze, S. (1974). Neuromyélite subaiguë avec névrite optique après chloroiodoquine: un nouveau cas. Annales de Médicine Interne (Paris), 125, 941-944.

Wadia, N. H. (1975). Some observations on SMON from Bombay. Paper presented to Fourth Asian and Oceanean Congress of Neurology, Bangkok, December, 1975.

Wadia, N. H. (1977). Some observations on SMON from Bombay. Journal of Neurology, Neurosurgery, and Psychiatry, 40, 268-275.

Worden, A. N., Heywood, R., Prentice, D. E.,
Chesterman, H., Skerrett, K., and Thomann, P. E. (1978). Clioquinol toxicity in the dog. Toxicology, 9, 227-238.

Yamamoto, S. (1978). Epidemiological evidence on the aetiology of SMON, with special reference to clioquinol. In Epidemiological Issues in Reported Drug-Induced Illnesses: SMON and other Examples, pp. 172-183. Edited by M. Gent and I. Shigematsu. McMaster University Library Press: Hamilton, Ontario.

Yoshioka, M., and Tamura, Z. (1970). On the nature of the green pigment found in SMON patients. Igaku no A yumi, 320-322 (in Japanese). 